\title{
Racial disparities in obesity for males \& females in three southern states in the US, across SES categories
}

\author{
Bisakha Sen*, Payal Patel-Dovlatabadi \\ ${ }^{1}$ Department of Healthcare Organization \& Policy, University of Alabama at Birmingham School of Public Health, Birmingham, \\ USA; "Corresponding Author: bsen@uab.edu \\ ${ }^{2}$ Public Health \& Director of Public Health Program, Department of Exercise and Sport Science, University of Evansville, Evansville, \\ USA
}

Received 28 September 2012; revised 30 October 2012; accepted 12 November 2012

\begin{abstract}
Objectives: Obesity rates in US are substantially higher among African-Americans than Whites. Racial disparities in obesity are sometimes ascribed to racial differences in socio-economicstatus (SES). We used data from three states in the southern region of the US with high rates of obesity, to examine the extent of racial disparities within SES categories, particularly examining whether disparities grow smaller at higher levels of income and education. Methods: We used data (2001-2009) from the Behavioral Risk Factor Surveillance System (BRFSS) for 79,676 respondents, African-American and white, from Mississippi, Alabama, and Louisiana. Multivariate logistic regressions were estimated. Analyses were conducted separately for males and females, for the full sample and by levels of education, income and aggregate SES. Risk-differences (RD), and Relative-Risk-Ratios (RR) were reported to enable inspection of magnitudes of racial gaps, which more conventional odds-ratios does not allow researchers to do. Results: The obesity-gap between African-Americans and Whites is larger for females than males. For males the gap becomes smaller and insignificant in higher education and income categories. For females, the gap remains statistically significant and is of comparable magnitude across all education and income categories. Conclusions: Racial disparities in obesity among males can be largely attributed to SES differences. However, racial disparities among females cannot simply be attributed to racial disparities in SES. Thus, reducing racial differences in income and education may not help reduce disparities in obesity
\end{abstract}

risk among White and African-American females. Further research is required to understand why racial disparities in obesity exist within specific SES categories for females.

Keywords: Race; Gender; Socioeconomic Status; Obesity Prevalence; Disparities

\section{INTRODUCTION}

Although the obesity epidemic affects the entire US population, disparities persist across race-ethnicity and socio-economic status (SES). Obesity rates among African-Americans and Hispanics are higher than those among non-Hispanic whites [1-3], with the disparities being greater among women than men [2]. Obesity prevalence is also inversely associated with socioeconomic status $[4,5]$. For example, there is strong evidence of associations between lower educational attainment and obesity [6-9] and lower income and obesity [6,7,10-14].

The simultaneous existence of disparities in obesity prevalence across race and across SES sometimes leads to the assumption that the higher obesity prevalence among African-Americans than whites is due to the lower income and educational attainment of AfricanAmericans compared to whites. Some studies have clearly shown that racial disparities in obesity exist within relatively homogenous SES groups for adolescents, and that the association between SES and obesity varies across ethnic groups-for example, SES tends to be inversely related with obesity-risk for Whites but less so for minorities $[14,15]$. Nonetheless, it is often surmised that racial disparities in obesity are largely an outcome of racial disparities in SES. For example, a Robert Wood Johnson Foundation report on obesity [16] explicitly stated that "Rates of obesity are significantly higher for Blacks and Latinos, reflecting long-standing 
disparities in income, education and access to health care" (our underline). The underlying implication is that the conditions correlated with being low-income-such as a lack of access to nutritious foods, and lack of parks/ sidewalks, and poor neighborhood safety-are the driving reasons for why minorities like African-Americans and Latinos are at a higher risk of obesity than non-Hispanic whites [16,17]. This in turn implicitly implies that racial disparities in obesity would decline if racial disparities in income, education and other SES indicators were reduced. What is still largely unexplored is the extent to which racial disparities in adult obesity exist within specific SES categories, and whether racial disparities are smaller or non-existent within higher SES categories [18].

This study contributes towards filling that information gap, by investigating the extent to which disparities in obesity-risk between African-Americans and non-Hispanic Whites (hereafter "Whites") exist within specific educational and income categories. Moreover, given existing evidence that racial disparities in obesity tend to vary by gender, and that the association of obesity and SES also differs between genders, this study separately analyzes disparities between African-American and White males and females within specific educational and income categories.

Data is drawn from three neighboring states that belong to the region of the US popularly referred to as "Deep South". This is the most obese region in the country $[19,20]$. The states include Mississippi, which has the highest obesity prevalence in the nation [19], and two neighboring states, Alabama and Louisiana. Focusing on this limited geographical region helps reduce potential confounding effects of regional variation in climate, culture, traditional diet, built environment and local economic conditions that could be challenging in a study that attempted to cover a larger geographical area where the racial distribution of the population also varied by region.

This study has important policy implications. If racial disparities in obesity are essentially a reflection of racial disparities in "income, education and access to health care", then policies that successfully address the latter should help alleviate the former. However, if racial disparities in obesity persist even within higher income and educational categories in this limited geographical area, then solutions beyond improving SES must be sought to address this issue.

\section{DATA \& METHODS}

The Behavioral Risk Factor Surveillance System (BRFSS) was established in 1984 by the Centers for Disease Control and Prevention (CDC). BRFSS is a state-based system of health surveys, where respondents are interviewed via telephone, and the information collected includes health risk behaviors, preventive health practices, and health care access specific to chronic disease and injury. States across the US use the BRFSS data to identify potential and emerging health problems and to develop, implement, and evaluate public health policies and programs [19]. The BRFSS samples represent the non-institutionalized adult population from each of the 50 states.

We utilized data from BRFSS for the three states of Alabama, Louisiana, and Mississippi from the biyearly time periods of 2001-2009. Basic demographic characteristics, BMI and obesity status, income levels, and education levels were included in the data analysis procedures. We retained Whites and African-Americans in our sample, but excluded 1355 Hispanics and "other" race groups, whose numbers were too small. The pooled sample sizes were 22,489 for Alabama, 27,057 for Louisiana, and 30,130 for Mississippi, giving a total study sample of 79,676 .

\subsection{Outcome Variable}

The dependent variable is a dichotomous indicator of obesity (obese if BMI $\geq 30$, not obese if BMI $<30$ ), derived from the categorization of BMI in BRFSS. A total of 3214 observations with missing BMI values were dropped from analyses. Overall 54,360 individuals were classified as "not obese" and 24,574 individuals were classified as "obese".

\subsection{SES Variables}

Our SES indicators are education and income. Education level categories were condensed into three categories: "high school or less", "some college", and "college". Similarly, income level categories were condensed into four categories: "less than $\$ 25,000$ ", "greater than $\$ 25,000$ but less than $\$ 50,000 "$ ", greater than $\$ 50,000$ " and "missing". Finally, a final "composite SES" categorization was created by combining the income and education information- "low SES" (education "high school or less" and income "less than $\$ 25,000 ")$, "high SES" (education "college" and income "greater than 50,000"), and "middle SES" (all others). The purpose of all of these alternate categorizations is to inspect whether our key findings are sensitive to exactly how SES is defined. Summary statistics of these variables are presented in Table 1.

Other variables in our statistical analyses included age, race, having health insurance, education level, income level, and time-trend. Because racial gaps in obesity prevalence vary across gender [21-23], we conducted all analyses separately for males and females. "Race" was 
Table 1. Proportions of key variables by gender.

\begin{tabular}{cccc}
\hline & Full Sample & Male & Female \\
\cline { 2 - 4 } & $\%$ & $\%$ & $\%$ \\
\hline Obese (BMI > 30) & 31.6 & 29.3 & 32.4 \\
Mean BMI & 28.1 & 27.9 & 28.1 \\
Have a Health Plan & 84.8 & 85.0 & 84.2 \\
Education Is High School or Less & 48.0 & & 49.5 \\
Education Is Some College & 25.9 & 46.7 & 26.2 \\
Education Is College Graduate & 26.1 & 25.3 & 24.3 \\
& By Income Categories & 28.0 & 35.2 \\
Income Is Less than \$25 K & 32.3 & 27.6 & 2.8 \\
Income Is \$25 K - \$50 K & 24.0 & 26.2 & 5.1 \\
Income Is Greater than \$50 K & 28.3 & 33.2 & 16.9 \\
Income Is Missing & 15.4 & 13.0 & 63.1 \\
Low SES & By SES Categories & & 12.7 \\
Middle SES & 22.3 & 19.1 & 24.2 \\
\hline
\end{tabular}

Source: BRFSS data for states MS, AL, and LA for biyearly years 2001-2009; "Low SES" includes those with education high school or less and have income less than $\$ 25 \mathrm{~K}$. "High SES" includes those who are college graduates and have income greater than $\$ 50 \mathrm{~K}$. All others are "Middle SES"; ${ }^{A}$ Further analyses shows that almost 60 percent who do not report income have High school or less in education, 22 percent have some college and 19 percent are college graduates. About 20 percent are white males, 49 percent are white females, 12 percent are African-American males, 19 percent are African-American females.

categorized as non-Hispanic White (hereafter White) or African-American. "Age" was measured as a continuous variable. "Health insurance" was a dichotomous variable indicating whether or not the respondent had a health insurance plan (the motivation for including this is to account for the possibility that people with access to a regular healthcare provider may receive better advice about maintaining a healthy weight). The "time" variable captured the year the data on that respondent was collected, starting from 2001. We also did separate analyses (results not shown) where we added variables that may mediate the relationship between SES and obesity, like diet (a binary indicator for 5 or more servings of fruits and vegetables per day) and physical activity (a binary indicator for whether the respondent met the recommended levels of physical activity).

\subsection{Statistical Approach}

Essentially, our approach is to compare differences in obesity prevalence for Whites and African-Americans, in the overall sample and also within each income and educational category. We start by conducting univariate analyses of the racial difference in prevalence of obesity for the full sample, and by income and education category. The results are in Table 2.

Our main statistical approach is using multivariate logistic regressions to estimate the racial gap in obesity risk for the full sample and for the specific income and educational categories. Regressions are adjusted for all additional variables described in "Other Variables".

We are interested not just in whether there is a statistically significant gap in obesity-risk between Whites and African-Americans, but also in the estimates of the magnitude of the gap. For binary outcomes, the magnitude can be measured using "relative-risk ratio" (RR) measured as $\mathrm{P}^{\mathrm{AA}} / \mathrm{P}^{\mathrm{W}}$, where $\mathrm{P}^{\mathrm{AA}}$ and $\mathrm{P}^{\mathrm{W}}$ are respectively the prevalence of obesity among the African-Americans and Whites, and the "risk difference" (RD), measured as $\mathrm{P}^{\mathrm{AA}}$ $\mathrm{P}^{\mathrm{W}}$. It is well-known that conventional odds ratios (OR) are not an acceptable, approximation of the "relative risk ratio" (RR) if the outcome (in this case, obesity) is not rare [24-28]. Hence, we apply the mathematical transformation proposed by Zhang and $\mathrm{Yu}$ [24] to convert the OR to estimates of RR. RD is widely used with logistic models in disciplines like economics, and sometimes 
Table 2. Univariate analysis of prevalence of obesity by race.

\begin{tabular}{|c|c|c|c|}
\hline & White $(\mathrm{N}=52,107)$ & African-American $(\mathrm{N}=26,827)$ & P-value \\
\hline$\%$ Obese & $\%$ & $\%$ & \\
\hline Full Sample, Male & 29.0 & 30.1 & 0.06 \\
\hline Full Sample, Female & 25.8 & 47.4 & $<0.001$ \\
\hline \multicolumn{4}{|c|}{ By Educational Categories: Male } \\
\hline Education Is High School or Less & 30.2 & 31.6 & 0.06 \\
\hline Education Is Some College & 30.0 & 29.4 & 0.23 \\
\hline Education Is College Graduate & 26.5 & 26.9 & 0.48 \\
\hline \multicolumn{4}{|c|}{ By Educational Categories: Female } \\
\hline Education Is High School or Less & 28.0 & 49.5 & $<0.001$ \\
\hline Education Is Some College & 26.0 & 45.7 & $<0.001$ \\
\hline Education Is College Graduate & 21.5 & 44.0 & $<0.001$ \\
\hline \multicolumn{4}{|c|}{ By Income Categories: Male } \\
\hline Income Is Less than $\$ 25 \mathrm{~K}$ & 28.8 & 32.4 & 0.006 \\
\hline Income Is $\$ 25 \mathrm{~K}-\$ 50 \mathrm{~K}$ & 28.6 & 29.5 & 0.90 \\
\hline Income Is Greater than $\$ 50 \mathrm{~K}$ & 30.1 & 28.6 & 0.015 \\
\hline Income Is Missing ${ }^{\mathrm{a}}$ & 27.9 & 27.85 & 0.97 \\
\hline \multicolumn{4}{|c|}{ By Income Categories: Female } \\
\hline Income Is Less than $\$ 25 \mathrm{~K}$ & 30.1 & 50.5 & $<0.001$ \\
\hline Income Is $\$ 25 \mathrm{~K}-\$ 50 \mathrm{~K}$ & 27.1 & 45.8 & $<0.001$ \\
\hline Income Is Greater than $\$ 50 \mathrm{~K}$ & 22.8 & 43.9 & $<0.001$ \\
\hline Income Is Missing & 22.07 & 44.06 & $<0.001$ \\
\hline \multicolumn{4}{|c|}{ By SES Categories: Male } \\
\hline Low SES & 30.22 & 34.01 & 0.002 \\
\hline Middle SES & 30.52 & 28.92 & 0.04 \\
\hline High SES & 27.95 & 26.52 & 0.39 \\
\hline \multicolumn{4}{|c|}{ By SES Categories: Female } \\
\hline Low SES & 31.46 & 52.79 & $<0.001$ \\
\hline Middle SES & 26.13 & 47.03 & $<0.001$ \\
\hline High SES & 22.37 & 44.61 & $<0.001$ \\
\hline
\end{tabular}

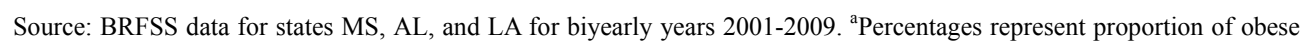
Non-Hispanic Whites and obese African-America in that specific gender, education, income or overall SES category. High, Middle and Low SES are as defined in Table 1.

referred to as "marginal effects". They are readily calculated by statistical packages like STATA (www.stata.com). We used STATA version 11 for our analyses. RR is probably more familiar to health scientists. However, it has the disadvantage that if, for example, the prevalence of disease $\mathrm{A}$ in one group is 3 percent of the sample and in the other group it is 1.5 percent, and the prevalence of disease $\mathrm{B}$ in one group is 40 percent and in the other group is 20 percent, then the RR for the first group relative to the second for both diseases will be 2 . The $\mathrm{RD}$, on the other hand, will be 0.015 in the first case and 0.20 in the second case, thus helping illustrate the fact that the second disease has a higher prevalence in the overall sample than the first. Therefore, on a topic that is likely 
to be of broad interest, providing both $\mathrm{RR}$ and $\mathrm{RD}$ may be useful to readers.

\section{RESULTS}

In our sample, 29.0 percent White males, 30.1 AfricanAmerican males, 25.8 percent White females and 47.4 percent African-American females qualified as obese. Univariate chi-square analyses found that the gender differences in obesity prevalence were significant for Whites and African-Americans at the 5\% level. Univariate chi-square analyses also found that the difference between White and African-American males fell just short of statistical significance at the $5 \%$ level $(p=0.06)$ in the full sample. In the sub-categories the difference was only significant in the Income less than $\$ 25 \mathrm{~K}$ category $(\mathrm{p}=0.006)$. Among females, the difference in percentage obese was highly significant in the full sample and in every category of education and income-level $(p<$ 0.001 in all cases).

The results from the multivariate logistic models show that, for both genders, African-Americans are at a statistically significant $(p<0.05)$ higher risk of obesity than Whites. The difference between the races is higher for females (RD: 0.204 and RR: 1.78) than males (RD: 0.023 and RR: 1.076). Among males, the racial difference is statistically significant among those in the "High school or less" educational category (RD: 0.026 and RR: 1.087 ), and in the "less than $\$ 25 \mathrm{~K}$ " income category (RD: 0.038 and RR: 1.135). For females, statistically significant racial differences persist across education and income level categories, including "income missing". In fact, the estimated sizes of the racial differences appear higher among females who are college graduates (RD: 0.22 and RR: 2.002) than those with some college (RD: 0.187 and RR: 1.723) or high school or less (RD: 0.204 and RR: 1.72). Similarly, the racial differences are higher among females with family income greater than $\$ 50 \mathrm{~K}$ (RD: 0.215 and RR: 1.95) compared to those with income between $\$ 25 \mathrm{~K}$ and $\$ 50 \mathrm{~K}$ (RD: 0.192 and RR: 1.713 ) and income less than $\$ 25 \mathrm{~K}$ (RD: 0.202 and RR: 1.67). Results remained largely unchanged in the multivariate models that additionally included the binary indicators for fruit and vegetable consumption, and physical activity (Table 3).

\section{DISCUSSION}

The disparity in obesity prevalence among AfricanAmericans compared to Whites is often attributed to the fact that African-Americans are, on average, disadvantaged in terms of education and income, which potentially restricts their ability to adopt healthy lifestyles like a good diet and adequate physical activity. This carries the implicit assumption that policies that bring income and education of African-Americans more at par with that of Whites can help reduce racial disparities in obesity. This viewpoint persists in spite of indications in some earlier studies that the relationship between race, SES, and obesity may be more complex [26]. In our study, we examine racial disparities among White and African-American females and males within specific income and educational categories, specifically examining whether the magnitudes of the disparities are smaller, similar or larger within higher income and educational categories. We estimate risk-ratios and risk-differences, which allows us to comment on the magnitudes, which odd ratios alone will not allow.

Using BRFSS data from 3 southern states with high obesity prevalence, we find that racial differences in obesity between African-Americans and Whites exist for both males and females, though the differences are larger among females. Among males, the racial disparities seem confined within the lowest educational and income category, and are by and large not existent for males who have at least some college education, and who have annual family incomes greater than $\$ 25,000$. In contrast, for females racial disparities persist across all educational and income categories. In fact, the magnitude of the gap actually appears highest among women who are college graduates, who have family incomes greater than $\$ 50,000$, or both. This persistent gap in obesity prevalence across SES categories suggests that improvements in educational attainment and income of African-American women may not suffice to solve the problem of racial disparities in obesity for females, but could contribute to reducing it substantially for males. This also suggests the need for research into racial differences in correlates of obesity - such as diet and physical activity - within specific income and educational categories.

How might one account for the persistence in racial differences in obesity for females across income and educational categories? It may also be that AfricanAmerican women have fewer incentives to attain a healthy BMI than their White counterparts. Some studies indicate that obese White women are more likely to face a wage penalty than obese African-American women [27], have lower self-esteem that obese African-American women [28] and face greater stigma and quality of life impairment [29-31]. Furthermore, Calle et al. [32] find that the association between high BMI (versus normal BMI) and RR of mortality is smaller and statistically weaker for African-American women than White women. The relatively lower economic, health and social costs of obesity faced by African-American women may give them less cause for personal concern about their weight. Indeed, self-perception of being normal weight versus overweight is less likely to be correct in African-American females compared to their White counterparts [33]. 
Table 3. Regression Results for african-americans (versus white) males and females: by ses indicators.

\begin{tabular}{|c|c|c|c|}
\hline Variable & Odds Ratio & Risk Difference & Relative Risk Ratio \\
\hline \multicolumn{4}{|l|}{ Full Sample, Male. } \\
\hline African-American & $1.11^{*}(\mathrm{p}=0.001)$ & 0.023 & 1.076 \\
\hline \multicolumn{4}{|l|}{ Full Sample, Female. } \\
\hline \multirow[t]{2}{*}{ African-American } & $2.45^{*}(\mathrm{p}<0.0001)$ & 0.204 & 1.781 \\
\hline & By Educational Categories & & \\
\hline \multicolumn{4}{|c|}{ Male, Education Is High School or Less. } \\
\hline African-American & $1.13^{*}(p=0.005)$ & 0.026 & 1.087 \\
\hline \multicolumn{4}{|c|}{ Male, Education Is Some College } \\
\hline African-American & $1.07(\mathrm{p}=0.262)$ & 0.014 & 1.048 \\
\hline \multicolumn{4}{|c|}{ Male, Education Is College Graduate } \\
\hline African-American & $1.13(\mathrm{p}=0.055)$ & 0.024 & 1.092 \\
\hline \multicolumn{4}{|c|}{ Female, Education Is High School or Less } \\
\hline African-American & $2.39^{*}(\mathrm{p}<0.0001)$ & 0.204 & 1.720 \\
\hline \multicolumn{4}{|c|}{ Female, Education Is Some College } \\
\hline African-American & $2.27^{*}(\mathrm{p}<0.0001)$ & 0.187 & 1.723 \\
\hline \multicolumn{4}{|c|}{ Female, Education Is College Graduate } \\
\hline \multirow[t]{2}{*}{ African-American } & $2.76^{*}(\mathrm{p}<0.0001)$ & 0.219 & 2.002 \\
\hline & By Income Categories & & \\
\hline \multicolumn{4}{|c|}{ Male, Income Is Less than $\$ 25 \mathrm{~K}$} \\
\hline African-American & $1.20^{*}(\mathrm{p}<0.0001)$ & 0.038 & 1.135 \\
\hline \multicolumn{4}{|c|}{ Male, Income Is $\$ 25 \mathrm{~K}-\$ 50 \mathrm{~K}$} \\
\hline African-American & $1.10(\mathrm{p}=0.079)$ & 0.020 & 1.069 \\
\hline \multicolumn{4}{|c|}{ Male, Income Is Greater than $\$ 50 \mathrm{~K}$} \\
\hline African-American & $1.04(\mathrm{p}=0.534)$ & 0.007 & 1.028 \\
\hline \multicolumn{4}{|l|}{ Male, Income Is missing } \\
\hline African-American & $1.07(\mathrm{p}=0.396)$ & 0.015 & 1.056 \\
\hline \multicolumn{4}{|c|}{ Female if Income Is Less than $\$ 25 \mathrm{~K}$} \\
\hline African-American & $2.35^{*}(\mathrm{p}<0.0001)$ & 0.202 & 1.671 \\
\hline \multicolumn{4}{|c|}{ Female if Income Is $\$ 25 \mathrm{~K}-\$ 50 \mathrm{~K}$} \\
\hline African-American & $2.33^{*}(\mathrm{p}<0.0001)$ & 0.192 & 1.713 \\
\hline \multicolumn{4}{|c|}{ Female if Income Is Greater than $\$ 50 \mathrm{~K}$} \\
\hline African-American & $2.71^{*}(\mathrm{p}<0.0001)$ & 0.215 & 1.950 \\
\hline \multicolumn{4}{|l|}{ Female, Income Is Missing } \\
\hline \multirow[t]{2}{*}{ African-American } & $2.73^{*}(\mathrm{p}<0.0001)$ & 0.198 & 1.977 \\
\hline & By SES Categories & & \\
\hline \multicolumn{4}{|l|}{ Male, Low SES } \\
\hline African-American & $1.23^{*}(\mathrm{p}=0.001)$ & 0.046 & 1.150 \\
\hline \multicolumn{4}{|l|}{ Male, Middle SES } \\
\hline African-American & $1.04(\mathrm{p}=0.228)$ & 0.010 & 1.033 \\
\hline \multicolumn{4}{|l|}{ Male, High SES } \\
\hline African-American & $1.16(\mathrm{p}=0.087)$ & 0.030 & 1.110 \\
\hline \multicolumn{4}{|l|}{ Female, Low SES } \\
\hline African-American & $2.38^{*}(\mathrm{p}<0.0001)$ & 0.209 & 1.667 \\
\hline Female, Middle SES & & & \\
\hline African-American & $2.53^{*}(\mathrm{p}<0.0001)$ & 0.200 & 1.809 \\
\hline Female, High SES & & & \\
\hline African-American & $2.85^{*}(\mathrm{p}<0.0001)$ & 0.203 & 2.025 \\
\hline
\end{tabular}

Source: BRFSS data for states MS, AL, and LA for biyearly years 2001-2009. "Represents significance at $\mathrm{p}<0.05$. Race reference group in all cases is "White". Models are adjusted for the control variables described in the paper, including age, time-trend measured in years, health insurance plan, education, and income categories. Analyses performed for specific income and education categories adjust for all the other control variables. The "income is missing" category is included as a control variable in the full sample analysis and analyses by educational categories. The "Risk Difference" estimates $\mathrm{P}^{\mathrm{AA}}$ - $\mathrm{P}$, holding the value of other model covariates at the sample mean (though this is easily changed, and our results are robust to small changes in values of other covariates). "Relative Risk Ratio" estimates $\mathrm{P}^{\mathrm{AA}} / \mathrm{P}^{\mathrm{W}}$, where $\mathrm{P}^{\mathrm{AA}}$ and $\mathrm{P}^{\mathrm{W}}$ are respectively the prevalence of obesity among the African-Americans and Whites. 
In addition, the persistence of the racial gap across SES categories could be partially driven by variables not measured in our study. For example, there is evidence that White families are more likely than African-American families with similar incomes to move into better neighborhoods [34], and African-American women express greater dissatisfaction with neighborhood quality and safety than Whites women even after controlling for SES [35]. Thus, in spite of having comparable income and education, African-American women may be more likely than Whites to live in neighborhoods with lack of access to healthy food or good physical activity facilities. Moreover, African-Americans may perceive themselves as marginalized in society due to experiences of discrimination, and there is evidence that such "subjective socio-economic status" is more strongly associated with health outcomes than objective SES measures (Operario et al., 2004; Knopp et al., 2004; Goodman et al., 2003). There may also be disparities in access to healthcare within SES categories that go beyond merely having health insurance coverage that our model does not adequately capture. On the other hand, it is not obvious why neighborhood quality, access to healthcare, and subjective SES should impact African-American women but not African-American men. Thus, on balance, we speculate that the more plausible reason may be the differences in quality of life or stigma associated with obesity for White women versus African-American women.

We acknowledge a number of study limitations. The BRFSS is a telephone-based survey therefore individuals without a residential phone were excluded. Additionally, BRFSS data are self-reported, and hence are subject to all the problems of self-reported data, including possible misreporting of height and weight (used to calculate BMI). There is evidence of underreporting of weight data among women respondents and over-reporting of height data among men in BRFSS [36,37], though no racial differences are reported in these patterns of underreporting or over-reporting. Finally, our data is from three southern states, and results may not be generalized to the whole country. However, we believe that these results should encourage similar research into racial disparities in obesity in other geographical regions of the US.

\section{CONCLUSION}

In conclusion, our findings show that disparities in obesity between non-Hispanic Whites and AfricanAmerican women in the South may not simply be attributed to disparities in income and education levels. This emphasizes the need to go beyond racial differences in SES when seeking the reasons underlying racial disparities in obesity. Only then may we be better able to formulate policies to address the issue of disparities in obesity.

\section{ACKNOWLEDGEMENTS}

This research was partially funded by 1RC2MD004778-01 "GO-ing Forward", NCMHD.

\section{REFERENCES}

[1] Centers for Disease Control and Prevention (2004) US Obesity Trends.

[2] Hedley, A.A., et al. (2004) Prevalence of overweight and obesity among US children, adolescents, and adults, 1999-2002. The Journal of the American Medical Association, 291, 2847. doi:10.1001/jama.291.23.2847

[3] Ogden, C.L. (2009) Disparities in obesity prevalence in the United States: Black women at risk. The American Journal of Clinical Nutrition, 89, 1001-1002. doi:10.3945/ajen.2009.27592

[4] Gortmaker, S.L., et al. (1993) Social and economic consequences of overweight in adolescence and young adulthood. New England Journal of Medicine, 329, 10081012. doi:10.1056/NEJM199309303291406

[5] Department of Health and Human Services (2001) The 2001 report on overweight and obesity.

[6] Jennifer, C., et al. (2011) Childhood obesity and educational attainment. A systematic review.

[7] Drewnowski, A. and Specter, S.E. (2004) Poverty and obesity: The role of energy density and energy costs. The American Journal of Clinical Nutrition, 79, 6.

[8] Karnehed, N., et al. (2006) Obesity and attained education: Cohort study of more than 700,000 Swedish Menast. Obesity, 14, 1421-1428. doi:10.1038/oby.2006.161

[9] Zhang, Q. and Wang, Y. (2004) Trends in the association between obesity and socioeconomic status in US adults: 1971 to 2000. Obesity Research, 12, 1622-1632. doi:10.1038/oby.2004.202

[10] Borders, T.F., Rohrer, J.E. and Cardarelli, K.M. (2006) Gender-specific disparities in obesity. Journal of Community Health, 31, 57-68. doi:10.1007/s10900-005-8189-8

[11] Schmeiser, M.D. (2009) Expanding wallets and waistlines: The impact of family income on the BMI of women and men eligible for the Earned Income Tax Credit. Health Economics, 18, 1277-1294. doi:10.1002/hec.1430

[12] Schoenborn, C.A., et al., (2002) Body weight status of adults: United States, 1997-98. US Department of Health and Human Services, Centers for Disease Control and Prevention, National Center for Health Statistics.

[13] Sharma, A.J., et al. (2009) Obesity prevalence among low-income, preschool-aged children-United States, 1998-2008. Morbidity and Mortality Weekly Report, 58, 769-773.

[14] Wang, Y. and Beydoun, M.A. (2007) The obesity epidemic in the United States - Gender, age, socioeconomic, racial/ethnic, and geographic characteristics: A systematic review and meta-regression analysis. Epidemiologic Reviews, 29, 6-28. doi:10.1093/epirev/mxm007

[15] Zhang, Q. and Wang, Y. (2004) Socioeconomic inequality 
of obesity in the United States: Do gender, age, and ethnicity matter? Social Science \& Medicine, 58, 1171-1180. doi:10.1016/S0277-9536(03)00288-0

[16] Levi, J., et al. (2010) F as in fat: How obesity threatens America's future: 2010: Trust for America's health.

[17] Joshu, C.E., et al. (2008) Personal, neighbourhood and urban factors associated with obesity in the United States. Journal of Epidemiology and Community Health, 62, 202-208. doi:10.1136/jech.2006.058321

[18] Duffy, P., Zizza, C. and Kinnucan, H. (2009) Obesity, BMI \& diet quality. How does the south measure up? http://ageconsearch.umn.edu/bitstream/46558/2/duffy-ziz za-kinnucan-saea-2009.pdf

[19] Centers for Disease Control and Prevention (2008) Behavioral risk factor surveillance system.

[20] Pan, L., et al. (2009) Differences in prevalence of obesity among Black, White, and Hispanic adults - United States, 2006-2008. Morbidity and Mortality Weekly Report, 58, 740-744.

[21] Gordon-Larsen, P., Adair, L.S. and Popkin, B.M. (2003) The relationship of ethnicity, socioeconomic factors, and overweight in US adolescents. Obesity, 11, 121-129. doi:10.1038/oby.2003.20

[22] Cawley, J. (2004) The impact of obesity on wages. Journal of Human Resources, 39, 451-474. doi: $10.2307 / 3559022$

[23] Averett, S. and Korenman, S. (1999) Black-white differences in social and economic consequences of obesity. Journal of the International Association for the Study of Obesity, 23, 166. doi:10.1038/sj.ijo.0800805

[24] Zhang, J. and Yu, K.F. (1998) What's the relative risk? The Journal of the American Medical Association, 280, 1690. doi:10.1001/jama.280.19.1690

[25] Holcomb Jr., W.L., et al. (2001) An odd measure of risk: Use and misuse of the odds ratio. Obstetrics \& Gynecology, 98, 685. doi:10.1016/S0029-7844(01)01488-0

[26] Katz, K.A. (2006) The (relative) risks of using odds ratios. Archives of Dermatology, 142, 761. doi:10.1001/archderm.142.6.761

[27] Schmidt, C.O. and Kohlmann, T. (2008) When to use the odds ratio or the relative risk? International Journal of Public Health, 53, 165-167.

\section{doi:10.1007/s00038-008-7068-3}

[28] Kleinman, L.C. and Norton, E.C. (2009) What's the risk? A simple approach for estimating adjusted risk measures from nonlinear models including logistic regression. Health Services Research, 44, 288-302. doi:10.1111/j.1475-6773.2008.00900.x

[29] Fallon, E.M., et al. (2005) Health-related quality of life in overweight and nonoverweight black and white adolescents. The Journal of Pediatrics, 147, 443-450. doi:10.1016/j.jpeds.2005.05.039

[30] Hebl, M.R. and Heatherton, T.F. (1998) The stigma of obesity in women: The difference is black and white. Personality and Social Psychology Bulletin, 24, 417-426. doi: $10.1177 / 0146167298244008$

[31] Lewis, T.T., et al. (2005) Race, education, and weight change in a biracial sample of women at midlife. Archives of Internal Medicine, 165, 545. doi:10.1001/archinte.165.5.545

[32] Calle, E.E., et al. (1999) Body-mass index and mortality in a prospective cohort of US adults. New England Journal of Medicine, 341, 1097-1105. doi:10.1056/NEJM199910073411501

[33] Paeratakul, S., et al. (2002) Sex, race/ethnicity, socioconomic status, and BMI in relation to self-perception of overweight. Obesity, 10, 345-350. doi:10.1038/oby.2002.48

[34] South, S.J. and Crowder, K.D. (1997) Escaping distressed neighborhoods: Individual, community, and metropolitan influences. American Journal of Sociology, 102, 1040 1084. doi: $10.1086 / 231039$

[35] Sen, B., Mennemeyer, S. and Gary, L.C. (2011) The relationship between perceptions of neighborhood characteristics and obesity among children. Economic Aspects of Obesity, 2011, 145-180.

[36] Yun, S., et al. (2005) A comparison of national estimates of obesity prevalence from the behavioral risk factor surveillance system and the National Health and Nutrition Examination Survey. International Journal of Obesity, 30, 164-170. doi:10.1038/sj.ijo.0803125

[37] Ezzati, M., et al. (2006) Trends in national and state-level obesity in the USA after correction for self-report bias: Analysis of health surveys. JRSM, 99, 250-257. doi:10.1258/jrsm.99.5.250 